\title{
Symbolic play in congenitally blind children
}

\author{
MARTIN BISHOP, R. PETER HOBSON, AND ANTHONY LEE \\ Tavistock Clinic, London; and University College, London
}

\begin{abstract}
There is controversy over the existence and nature of blind children's limitations in symbolic play. In this study we tested 13 5- to 9-year-old congenitally blind children for the ability to symbolize when an adult provided scaffolding for their play. The blind children were selected on the basis that they did not have the syndrome of autism, and they comprised two groups matched for age (MA) and verbal ability on the Wechsler Intelligence Scale for Children who contrasted in their ability to engage in social relations. We also tested a group of sighted children who were MA matched with the more socially able blind children. On the basis of an hypothesis about the social-developmental sources of symbolic play deficits in congenitally blind children, we predicted differences between the socially able and socially impaired groups of blind children in the following respects: the attribution of symbolic meanings to play materials, the ascription of individual roles to play figures, and the anchorage of play in the scenario as presented by the adult. The results accorded with these predictions. Whereas the more socially able blind children showed symbolic play that was very similar to that of sighted children, the MA- and IQ-matched socially impaired blind children were limited in the three aspects of their play. On the other hand, even the socially impaired children showed instances of symbolizing. The findings suggest a way to reconcile conflicting reports of symbolic play deficits in young blind children, and may be relevant for explaining the association between autism and congenital blindness.
\end{abstract}

There are two reasons to study the development of symbolic play in congenitally blind children. First and most obviously, such study is important for understanding an area of blind children's cognitive functioning that is relevant for broader psychological domains such as language and social relations. Here the emphasis is on what we can learn about blind children, and our conclusions may carry implications for intervention with affected indi-

This study was supported by a PhD studentship from the Mary Kitzinger Trust to Martin Bishop. The Hayward Foundation also contributed financial support. We thank the pupils and staff of the following schools, who were so generous in making the study possible: Dorton House School, Sevenoaks; West of England School, Exeter; Joseph Clarke School, London; Linden Lodge School, Wimbledon; Temple Bank School, Bradford; St. Vincent's School for the Blind, Liverpool; RNIB Sunshine House School, Northwood; and Priestley Smith School, Birmingham.

Address correspondence and reprint requests to: R. Peter Hobson, Adult Department, Tavistock Clinic, 120, Belsize Lane, London NW3 5BA, UK; E-mail: r.hobson@ ucl.ac.uk. viduals. For example, clinicians stress how symbolic play fosters sighted children's capacity to manage their own feelings and be open to others (e.g., contributions to Slade \& Wolf, 1994), and if there are abnormalities in blind children's play, then it may be possible to identify these and ameliorate potentially untoward consequences.

Second, the study of any psychological ability in a group of atypically developing children may be revealing for the nature and development of the ability in question, in this case, the ability to play. Pioneer developmentalists such as Piaget (e.g., 1962), Vygotsky (1976), and Winnicott (1971), through to more recent writers such as those represented in edited works by Bretherton (1984) and Smith and Franklin (1979) or reviewed by Fein (1981), have focused on the origins and implications of symbolic play in typically developing children. Early expressions of such play include children treating a doll as the passive recipient of their actions at around 17 months of age, and giving the doll independent agency 
toward the end of their second year (e.g., Wolf, Rygh, \& Altschuler, 1984). In recent years, perspectives from developmental psychopathology have complemented such accounts. Of particular significance for the present paper is the striking association between abnormalities in interpersonal relations and creative symbolic play that occur in early childhood autism (e.g., Hobson, 1990; Leslie, 1987; Lewis \& Boucher, 1988; Wing \& Gould, 1979; Wulff, 1985). Research on play in a further group of atypical children (those with congenital blindness) promises not only to shed light on the social-developmental basis for symbolic play in typically developing children, but also to further our understanding of the deficits observed in autism.

What, then, is the evidence that blind children have deficits in symbolic play? Much of the literature on play in blind children consists of clinical reports of single or small numbers of cases, and the modest number of more systematic studies provide only a schematic picture of the children's abilities. The most vivid account, and one that influenced our own methodological approach, is that provided by Fraiberg (1977). Fraiberg and Adelson (1977) described an able child, Kathie, who was congenitally totally blind from retrolental fibroplasia (retinopathy of prematurity), and who showed marked limitations in symbolic play. When just over 3 years old, for example, Kathie was provided with a small basin of water, a doll, and a towel as play materials, and encouraged to give dolly a bath. Initially, Kathie showed little interest, and then as soon as she touched the water, she herself stepped into the tiny tub, and began to chant her own bathtime songs. Even when Fraiberg introduced prompts such as suggesting that Kathie wash dolly's hair and having the doll protest with "No, no, I don't want a shampoo," Kathie failed to pick up the game. Only later in her life, after she reached the age of 4, did Kathie began to represent herself in doll play. Yet Kathie was definitely not autistic, and once developed, her imaginative play was highly inventive.

Further clinical-descriptive accounts fill out this picture. Wills $(1965,1968,1979 a, 1979 b$, 1981), who considered that blind children are delayed in the ability to symbolize, noted the children's tendency to regress to simple repetitive activities (see also Burlingham, 1961), and pointed out how often their play is an exact repetition of some event. Sandler and Wills (1965) emphasized that although blind children can often say what their caregivers or other people may say to them, they are less able to enact the role of someone else, and early attempts at role play lack the constant reversal of roles that is familiar in the play of sighted young children (also Sandler \& Hobson, 2001). Parallel difficulties in reversing roles have been reported in blind children's language (see Andersen, Dunlea, \& Kekelis, 1984; and Hobson, 1993a, 2000, for discussion). On the basis of longitudinal observations of preschool visually impaired children in Sweden (e.g., Preisler, 1991, 1993, 1995; Preisler \& Palmer, 1989), Preisler (1993, p. 307) wrote the following: "From all the observations made at the nurseries, the blind children never spontaneously took part in the sighted children's symbolic plays or role plays ... during the age period 2-3 years, three of the eight observed blind children engaged in simple pretend play ... Karin engaged in symbolic play when she was 4 years old, while the other children were older, between 5 and 6 years. With few exceptions, the children were only observed to engage in symbolic play with adults." Evidence for limited symbolic play also emerged from a study by Hughes, DoteKwan, and Dolendo (1998), who recorded an average of $7 \mathrm{~min}$ of videotape of solitary play at home for each of 13 visually impaired children who were 3 and 4 years old. Symbolic play, defined as using objects in a way the differed from the original intended use such as pretending a block is a car and driving it home, accounted for less than $4 \%$ of play, and was shown by only two individuals (and by none of the most visually impaired children) despite the children's relatively typical development in other respects. Therefore, it seems there may be substantial delays in the development of symbolic play in blind children, and some limitation in the form of such play when it emerges.

There are no systematic studies documenting the prevalence of deficits in symbolic play 
among blind children. Reports such as those of Ferguson and Buultjens (1995), Troster and Bambring (1994), and Schneekloth (1989) focussed upon the relative dearth of collaborative social play among visually impaired children, rather than on symbolic play per se. Brown, Hobson, Lee, and Stevenson's (1997) study of autistic-like features in congenitally blind children (4-9 years old) revealed abnormalities in interactive play and type of play even in blind children of higher IQ; according to systematic teacher reports on a nonautistic subgroup of 15 blind children, 4 showed poor imaginative play. In contrast, an intensive study of 9 congenitally blind children (5-9 years old) with autism and 9 matched sighted children with autism (Hobson, Lee, \& Brown, 1999) revealed that 7 of the blind children (and only 2 of the sighted group) showed evidence of pretend acts. However, in only 1 blind child was this elaborated into a theme, and none of these blind children used one object to represent another.

There is reason to exercise caution in interpreting reports of symbolic play in blind children. First, nearly all studies and reviews (e.g., those of Parsons, 1986, and Ferguson \& Buultjens, 1995) concern children with varying degrees of visual impairment. This may be problematic because there is reason to believe that even very modest amounts of sight, or sight for even very short periods after birth, may make a substantial difference to children's development (Preisler, 1991). Second, investigators have not attended closely to their definitions of symbolic play, for example, tending to record all instances of pretend play as symbolic, whether or not the children attributed pretend properties to symbolic vehicles. As one could observe in the case of Kathie, blind children may be able to enact scenes in pretend, even using props, without yet being able to make an object serve as the symbolic vehicle for meanings in the flexible way that is a feature of most sighted children's play. Ferguson and Buultjens (1995) noted that that some of the younger children in their study used language and sounds as a means of expressing "pretend" play, and concluded that, although manifest in a different form, symbolic play is not necessarily delayed. Yet, evidence such as
Tait's (1972b) observations that visually impaired children assigned fewer and less varied "roles" to props like a cardboard box than did sighted children, might suggest that atypical forms of mental representation underpin such behavior in blind children.

Third, it is important to appreciate the existence and theoretical importance of individual differences in the play abilities of blind children, and to appreciate how deficits may lessen over time. Rogers and Puchalski (1984) studied 16 visually impaired children between the ages of 18 and 38 months for involvement in symbolic play led by the investigator (who pretended to drink juice from a cup, and enacted "scenarios" such as bathing a doll and a bedtime scene with a variety of props, guiding the children's hands), and reported a mixed picture of delays and abilities. For example, just 6 children were able to demonstrate symbolic acts in the scenarios, and three more did so in the simple prompted actions, but the children also showed fewer and less diverse symbolic schemes than expected of typically developing 20-month-old children. Lewis, Norgate, Collis, and Reynolds (2000) investigated 18 children with visual impairments between 21 and 86 months on two structured tests of play, but when 4 children who met the diagnostic criteria for autism and one other nonperforming child were excluded, which meant that only 7 of the remaining children had profound visual impairment, there was evidence of impaired functional play (appropriate play with toys which are physically similar to everyday objects but of a different size), but only modest evidence of discrepancy between chronological age and the ability to attribute symbolic meanings. However, given the ages of the children tested, mostly well above those at which typically developing children are showing symbolic play, and in the light of other evidence cited above, it seems premature for the authors to conclude that "symbolic play skills are intact" (Lewis et al., 2000, p. 459) in children with visual impairment.

The aim of the present study was to examine whether there are abnormalities in the symbolic play of congenitally blind children aged between 5 and 9 years of age who do not also 
present with the syndrome of autism. We do not presume that blind children with autism are in a distinct category from the remaining population of blind children; on the contrary, we consider that at least a proportion of such cases represent the extreme end of a continuum, and have argued that blindness itself contributes to "autistic" impairments that include deficits in symbolic play (Hobson, Brown, Minter, \& Lee, 1997; Hobson et al., 1999). However, if we were to have included children with the syndrome of autism in the present study, it would have been open to interpret the results as reflecting "autism" per se, rather than having anything to do with blindness.

In fact, the focus of our study was at once more restricted and yet more ambitious than documenting the nature of symbolic play in congenitally blind children. It was more restricted in the sense that we concentrated upon specific facets of symbolic play, and especially the anchorage of symbolic meanings in the materials of play, and the ascription of roles to play characters. It was more ambitious in the sense that we wished to examine whether there is a relation between blind children's social impairment and their abilities in symbolic play.

Our background hypothesis was that blind children may be handicapped in developing creative symbolic play by virtue of their difficulty in seeing how other people relate to things and events in a shared world, and identifying with others' psychological orientation. This would mean that they are handicapped in discovering how people ascribe new meanings to objects that have an alternative, "objective" meaning. We also hypothesized that the handicap is most severe for those who are also less strongly or affectively engaged with other people's attitudes to the world, for the reason that this further limits their propensity to identify with such attitudes to objects and events. We anticipated that "socially able" children of the age and cognitive ability studied here would have overcome much of the handicap they might have suffered in this regard, so that there would be few if any substantial differences between their symbolic play and that of matched sighted children. On the other hand, we predicted that when socially im- paired blind children were compared with socially able blind children of the same age and cognitive ability, the former group would show deficits in symbolic play. In other words, we believe that in some children, congenital blindness may constitute a contributory but not sufficient factor for the development of symbolic play deficits, as indeed for the development of other features of autism.

Thus, our methodological approach was to employ one group of blind children as a control group for another group of blind children. We reasoned that if there were group differences, one could infer that these arose not as inevitable (and perhaps theoretically uninteresting) side effects of blindness, in that the two groups were "matched" for blindness, but would instead reflect an abnormality to which both blindness and social impairment might have contributed.

We accepted that our two groups of matched children would be small in size, although we should also stress that the total number of congenitally blind children studied here is substantially larger than in previous studies and the sample is unusual because of our strict inclusion criteria for near-total blindness from birth. In addition, we accepted that, as a result, we could only test a small number of predictions about the nature of group differences. Therefore, we specified our principal predictions in advance and have treated the statistics that we applied to any other aspects of the results as tentative and suggestive only.

Our predictions concerned the comparisons between the socially impaired and socially able blind children. We predicted that even when the children were matched for age and for cognitive ability, those who were socially impaired would show (a) less attribution of symbolic meanings to play objects, (b) less evidence of individual roles anchored in play objects, and (c) less anchorage in the play scenario as presented by the adult. We anticipated that this pattern would be evident both in overall ratings of play, and when the very best instances of play from each child ("peak ratings") were considered. The point of this latter set of ratings was to determine whether the children lacked the potential to produce each form of play, or whether there 
was indication that they could score highly at some points of their play.

\section{Study 1: A Comparison Between Socially Able and Socially Impaired Blind Children}

\section{Participants}

The participants in this study were seven socially able and six socially impaired congenitally blind children attending schools for visually impaired children around England. We selected potential participants on the basis that they had been blind or had minimal light perception from birth; were aged between approximately 6 and 9 years; and did not have coincident neurological impairments, a diagnosis of autism, or reported comorbidity (although we did not conduct systematic screening beyond information available from teachers and case notes). Through detailed discussions, two qualified class teachers of these children were asked to rate the social abilities of the children according to a 5-point scale (from $5=$ very good, $3=$ moderate, to $1=$ poor; the kappa coefficient of reliability for the two independent judges was .64, indicating substantial agreement), according to "the children's ability to relate to others (adults or peers), establishing normal interpersonal contact with them." This enabled us to select those children into one group who scored a mean of 4.5 or above out of 5 on the two teacher ratings (the High Social [HS] group), select another group who scored 3 or below on the ratings (the Low Social [LS] group), and exclude all children who were intermediate in scores. At this point we administered the verbal subtests of the Wechsler Intelligence Scale for Children-Revised (WISC-R), so that we could arrive at two groups who were group matched for age and IQ (and therefore for verbal mental age). Finally, we applied the Childhood Autism Rating Scale (CARS; Schopler, Reichler, \& Renner, 1988), omitting Item VII on visual responsiveness, to videotaped interactions of the children playing with the investigator, to confirm that none of the children met the diagnostic criteria for autism, which is generally taken to correspond with a
CARS score of 30 or above (or 28 and above with the item omitted).

The participant characteristics of the two resulting groups are given in Table 1. Here it can be observed that the groups were similar in age and IQ, but different in the teachers' ratings of sociability and CARS scores. It is of note that three of the HS group but only one of the LS group had retinopathy of prematurity, and none of the HS group but four of the LS group had Leber amaurosis. The participant characteristics might also be compared with those seven children (four male, three female) who had been excluded from the study because they fell into the intermediate category of "moderately social" (mean teacher score = 3.6 out of $5, S D=0.3$ ); here, four children had a diagnosis of retinopathy of prematurity, one had Leber amaurosis, one had optic nerve hypoplasia, and one anophthalmia, and this group had a mean chronological age (CA) of 85 months ( $S D=7$ months), an IQ of 94 $(S D=10)$, and a mental age (MA) of 79 months ( $S D=7$ months).

\section{Study 1 Procedure}

Children were tested in a quiet room at school. There was a single play session lasting about $20 \mathrm{~min}$, and this was videotaped. The experimenter and child sat on the floor, and the experimenter introduced the task materials in a fixed order, as follows:

\section{Task 1: Play with a single doll}

The materials for this task were a $25-\mathrm{cm}$ doll made of pliable plastic, chosen for its naturalistic "cuddleable" quality and with a simple dress that was easy to remove, a box lid that was slightly longer in length and width than the doll, a $30 \times 30 \mathrm{~cm}$ flannel, a paper napkin, a small clear plastic open bottle, a plasticcovered pad and a washing-up bowl.

Spontaneous play. Each of the the objects was handed to the child in turn, and the child was encouraged to examine them. Then the doll was introduced: "This is Ann. Do you want to play with Ann? What do you want to play 
Table 1. Participant characteristics

\begin{tabular}{|c|c|c|c|c|c|c|c|}
\hline Child & Gender & $\begin{array}{c}\text { CA } \\
\text { (months) }\end{array}$ & IQ & $\begin{array}{c}\text { MA } \\
\text { (months) }\end{array}$ & Diagnosis & $\begin{array}{l}\text { CARS } \\
\text { Score }\end{array}$ & $\begin{array}{c}\text { Teachers' } \\
\text { Social } \\
\text { Ratings } \\
(\max =5)\end{array}$ \\
\hline \multicolumn{8}{|c|}{ High Social Group } \\
\hline 1 & M & 91 & 77 & 85 & Retinopathy of prematurity & 14 & 4 \\
\hline 2 & M & 92 & 80 & 87 & Retinopathy of prematurity & 14 & 4.5 \\
\hline 3 & M & 79 & 76 & 96 & Retinopathy of prematurity & 14 & 5 \\
\hline 4 & M & 93 & 94 & 101 & Uncertain: optic pathway disorder & 14.5 & 4 \\
\hline 5 & M & 75 & 82 & 109 & Microphthalmia (prostheses) ${ }^{a}$ & 15.5 & 5 \\
\hline 6 & $\mathrm{~F}$ & 107 & 57 & 61 & Optic atrophy: hydrocephalus & 14 & 5 \\
\hline 7 & M & 96 & 112 & 117 & Retinal aplasia & 15 & 5 \\
\hline Mean & & 90.43 & 93.14 & 83.14 & & 14.43 & 4.64 \\
\hline$S D$ & & 10.67 & 19.58 & 16.03 & & 0.61 & 0.48 \\
\hline \multicolumn{8}{|c|}{ Low Social Group } \\
\hline 1 & $\mathrm{~F}$ & 87 & 72 & 63 & Retinopathy of prematurity & 21 & 3 \\
\hline 2 & $\mathrm{~F}$ & 77 & 96 & 74 & Leber amaurosis & 23 & 2.5 \\
\hline 3 & M & 70 & 106 & 74 & Leber amaurosis & 25.5 & 2.5 \\
\hline 4 & M & 103 & 85 & 88 & Leber amaurosis & 26 & 3 \\
\hline 5 & M & 94 & 100 & 94 & Leber amaurosis & 17.5 & 3 \\
\hline 6 & $\mathrm{~F}$ & 105 & 112 & 118 & Norrie disease & 22 & 3 \\
\hline Mean & & 89.33 & 95.17 & 85.17 & & 22.50 & 2.83 \\
\hline$S D$ & & 14.04 & 14.59 & 19.52 & & 3.13 & 0.26 \\
\hline
\end{tabular}

Note: CARS, Childhood Autism Rating Scale (omitting Item VII on visual responsiveness). A score of 14 means no abnormality; a score of 30 is the conventional cutoff for autism.

${ }^{a}$ An isolated condition, not part of a wider syndrome or association.

with Ann?" The intention of this open-ended question was to prompt spontaneous use of the play materials. As in all subsequent conditions, the experimenter allowed play to proceed for up to 5 min with nonspecific input except for comments of approval, and made two requests for anything else the child might like to do if the play lapsed; but we rated only the first 2 min of play, whilst the children were most engaged.

Structured play. At this point the experimenter said: "Can I make up a story with Ann?" He took the doll and proceeded to guide the child through a sequence of setting up a pretend bath scenario. The child was encouraged to feel each object as it was labeled, and to shadow the experimenter physically as he acted out the following narrative:
"I'm going to get Ann ready for a bath, and then it's bedtime. Here's her bed (box) and her blanket (flan$n e l$ ), let's put them away on the side until later... Now into the bathroom, here's the bath, let's get Ann undressed, take Ann's clothes off; take her dress off, put her clothes down by the bath, sit Ann down by the bath (bowl), get Ann's towel (napkin) ready, put the soap (plastic pad) by the bath, turn the hot water on (mimed), turn the cold water on, sshhhhhh (stir the water); put some bubble bath (clear bottle) in, feel the water, wwisshhh it around, just right, turn the hot water off, turn the cold water off, put Ann in the bath." This was followed by, "Now that we've got Ann ready for a bath, can you give her a bath?", and the child was encouraged to take over control of what happened. After the child's play had ceased, the experimenter said: "And then it's bed-time. Can you get Ann ready for bed? Make up what happens next." The child was helped to take the flat box and flannel, and approximately 5 min was allowed for her own contribution. 


\section{Task 2: Play with two miniature figures}

Here our aim was to allow the children to demonstrate whether they would enact reciprocal role relationships with figures in play. For these purposes we framed a scenario involving two children in school at playtime.

Spontaneous play. Once the materials of the first task were removed, the child was given a $40 \times 25 \times 13 \mathrm{~cm}$ open-ended box with a square hole cut out of the middle of one of its sides to represent a doorway into a building. Two small wooden skittles (each $6 \mathrm{~cm}$ high) were introduced into the child's hands as the experimenter said "Here are two children ... and they're at school, this is a classroom (drawing the child's hands over the box). Can you make up a story with the two children and tell me what happens?" Once again, the child was given two prompts to continue, until no further play was produced; and again only the first 2 min were rated.

Structured play. At this point the experimenter took the initiative: "Let's pretend that this is Karen and Jane (or Mark and John, when a boy was tested), and they are outside the classroom in the playground. Karen is having a drink, and Jane says, "Can I have a drink, Karen?” And Karen says, "No. It's mine! You can't!" And Jane says, "Please!” And Karen says "No! You can't! It's my drink and you can't have any!" This scenario was acted out in an animated way, and the children were encourage to feel the figures as the experimenter moved them up and down as they spoke with excited voices. Then, as before, the children were asked to make up what happened next, and were rated for the first 2 min of play.

\section{Study 1 Measures}

For each of the four conditions, the first $2 \mathrm{~min}$ of videotaped play were rated and analyzed (given that in some participants, play lapsed subsequently). The first author's ratings were employed in the analyses: for assessing reliability, $100 \%$ of the ratings were subsequently made independently by a colleague who was unaware of the hypotheses and predictions of the study, and blind to which group (HS or LS) the participants belonged. A rating schedule was specially designed for the study, and on each of the ratings outlined below, judgments were made on 5-point scales. First, there was an overall rating for the 2-min play episode; second, there was a "peak rating" of the highest score that might have been given for any specific event within the play. Therefore, if a given child gave only one brief instance of role play anchored in the play materials, that individual's peak rating could be high, even though the overall rating might be lower.

\section{Preliminary assessment of attentiveness to play materials}

The purpose of this rating was to assess whether the children attended to the play materials at all. Here the judgment was made regardless of the way in which the materials were handled or treated, or any utterances that the child made. For example, the children might use the objects for their customary function.

\section{Measures that were the focus of directional predictions}

Attribution of symbolic meaning to the play materials. The intention was to assess how far any symbolic play was physically anchored in the materials provided, rather than occurring on a purely verbal level. Following Leslie (1987; see also Lewis et al., 2000), symbolic play was defined as either (a) pretending one object was another, (b) attributing novel properties to an object, or (c) pretending that an absent object was present. The judgment was confined to the application of pretend meanings to the materials provided. Examples are as follows: score 5, a child who could use the materials to represent bathroom items for the doll, which was given an identity; score 3 , a child who gave some meanings to play materials (e.g., referring to the doll's nightie), but for whom this seemed only loosely connected with her play actions (e.g., the doll was treated impersonally), and where it was difficult to be confident that "pretending" was sustained 
rather than reporting of the child's own experiences; score 1, a child who for Task 2, initially held the figures resting in her limp hand, which lay open palm upward on the floor, and subsequently brought them to the box without manifest representational meaning.

Individual roles anchored in the play materials. The judgment concerned the extent to which personal roles were attributed to the doll in Task 1 and the miniature figures in Task 2. The issue was whether the child was playing "through" the figures, giving them roles as people (regardless of whether they related to each other reciprocally). Once again, positive ratings were confined to instances in which the child ascribed roles to the play materials, and in this way anchored the symbolic meanings that $\mathrm{s} /$ he was attributing. Examples are score 5, a child who attributed personal qualities to the doll, for example, asking it with a caring voice, "Would you like to play 'Head and shoulders?'," and showing the doll bath items; score 3, a child who began by fiddling with the foot of the doll, responded to a question about what happens next by saying "Pull the plug out now that Anne is in bed," and only at the end of the play addressed the doll with "And you go to bed quietly"; and score 1, a child who tapped the play figures together but gave no indication that they were human characters.

Anchorage in the scenario as presented. This rating concerned the extent to which the child's own narrative contribution maintained the theme of the scenario as presented. Usually this took the form of a verbal account to augment actions with the play materials. Examples are: score 5, a child who said to the doll: "Got to get you into bed now," placed the doll on the tray representing the bed, and said: "See you in the morning. Good night, Anne"; score 3 , a child who in the second task, appeared to use the figures as two interacting characters, but who made no reference to the classroom scene; and score 1, a child who made no reference to the presented scene, when asked what was happening said: "Drink," and merely placed the figures into the box provided.

\section{Additional observations}

It is important to stress that a priori, we distinguished between our specific and directional predictions on the one hand, and the following exploratory examination of the data on the other. The reason we limited our principal analyses to three components of play, was to avoid the danger of conducting too many comparisons and therefore losing the chance of capturing significant differences on the critical variables. The following two features of play were rated to provide an additional perspective on the "personal meaning" that a child was able to impart to the doll or miniature figures:

1. For Task 1 only: Affective relation toward doll. This rating concerned the degree to which the child showed an "emotional" relation with the doll as a symbolized person.

2. Ascribing individual character(s) to the doll(s) in the narrative. Here the emphasis was on the degree of "personhood" and identity attributed to the characters established in play, rather than whether a child enacted a role through the figure.

\section{Interrater reliabilities}

The two raters assessed each and every child on each condition of the task, and according to all measures noted above. The 5-point scales for each ranged from $5=$ consistently high performance, $3=$ moderate symbolic skills, to $1=$ very poor performance. The training of the raters involved the use of videotapes from unmatched blind and sighted children of mixed abilities who were not participants in the study. On the preliminary measure that involved judgments of the children's attention to the task, the kappa coefficient was .86 for two independent ratings of all the children, indicating "almost perfect agreement" according to Landis and Koch (1977). On the measures that were the focus of our principal predictions (the attribution of symbolic meaning, the ratings for individual roles anchored in the $\operatorname{doll}[\mathrm{s}]$, and play anchorage in the scenario as presented), the kappa coefficients ranged between .93 and .98 , and for the ratings of peak performance, 
between .98 and 1.00 . In the additional, exploratory ratings, kappa coefficients ranged between .92 and .95 .

\section{Study 1 Results}

\section{Preliminary assessment of attentiveness to play materials}

There was not a significant group difference on ratings for attentiveness to the play materials. The mean ratings for all children on each task exceeded 4 out of 5, and without exception the peak ratings were at the ceiling. Therefore, the remaining observations were not attributable to inattentiveness in either group.

\section{Measures that were the focus of directional predictions}

The results for the overall ratings of (a) the attribution of symbolic meaning to play objects, (b) individual roles anchored in play objects, and (c) anchorage in the scenario as presented, are given in Figures 1 and 2. We had made directional predictions in each respect, and applied one-tailed tests. Owing to the fact that no scenario was presented in the first part of Task 1, where a doll had a bath, there were no data on anchorage here.

In Task 1 it may be observed that with one exception (anchorage in the scenario as presented, where scores approached ceiling), both in relation to spontaneous and structured play, there were significant group differences in the predicted direction. Whereas most of the HS children achieved scores at the upper end of the scale in each respect, there was much more variability among the LS children.

In Task 2 there were significant group differences in the predicted direction in relation to the spontaneous play. In the structured play, the group difference for attribution of symbolic meanings in the play and individual characters anchored in the dolls failed to reach statistical significance, but were strongly directional. The groups were significantly different in the ratings of anchorage in the scenario as presented in the structured play.

By way of informal observations, it is notable how, as one might expect, the structured condition of Task 1 tended to prompt more elaborate play in the majority of the children in each group: when given a narrative to frame the play, a substantial proportion of the HS children achieved ceiling or near-ceiling scores and fewer of the LS children scored at the lower end of the scale of scores, both for the attribution of symbolic meanings to play objects and for individual roles anchored in play objects. Less expected was the result on Task 2, where the experimenter's attempt to structure a scenario among the figures in the playground scene appeared to reduce the children's ability to sustain the attribution of meaning to the play objects, and to ascribe individual roles. This seemed especially to be the case among the LS children, in that four out of six were given the lowest possible scores on these measures.

The results so far have concerned overall ratings of the children's play. We were also interested in the "peak performance" of the children in their spontaneous play, that is, the maximum score they might be given for any part of this play, and an index of the degree to which they might demonstrate potential ability. The results for spontaneous play are presented in Table 2 (where the group differences for the attribution of symbolic meaning to play objects in Task 1, and scores for individual roles anchored in play objects in Task 2, are significant at $p<.01$ and .05 , respectively, on Mann-Whitney tests). Here it may be observed that whereas all the HS children showed clear instances of anchored symbolic play involving individual social roles, the peak performance of LS children were spread across the possible range of scores. When subsequently prompted in the structured form of Task 1 (bathing Anne), over half of the LS (along with all the HS) children also achieved peak scores of 4 or 5 on each of the three symbolic play measures; and although prompting failed to improve their peak scores in Task 2, these results indicate the potential for some degree of symbolic play, albeit inconsistent, present in many of the LS children.

\section{Additional measures}

Task 1: Affective relation toward doll. In the spontaneous condition, the mean for the HS 
Spontaneous Play

Prompted Play

ATTRIBUTION OF SYMBOLIC MEANING TO PLAY OBJECTS
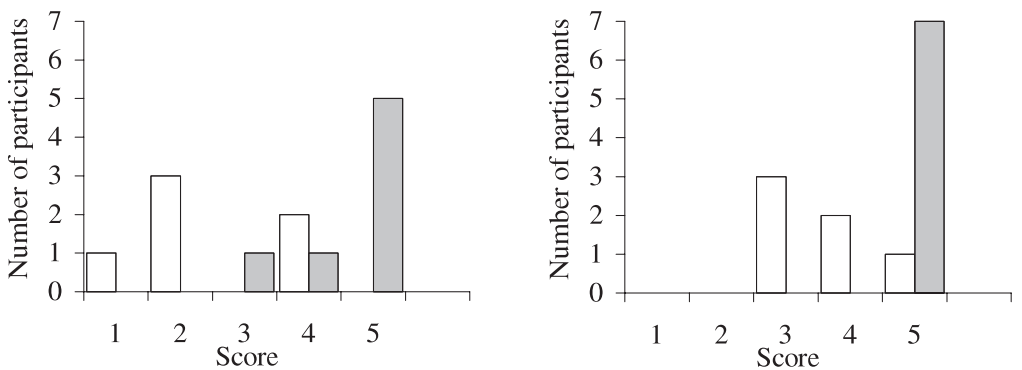

$\mathrm{U}=3.0, \mathrm{p}<0.01$

$\mathrm{U}=3.5, \mathrm{p}<0.01$

INDIVIDUAL ROLES ANCHORED IN PLAY OBJECTS
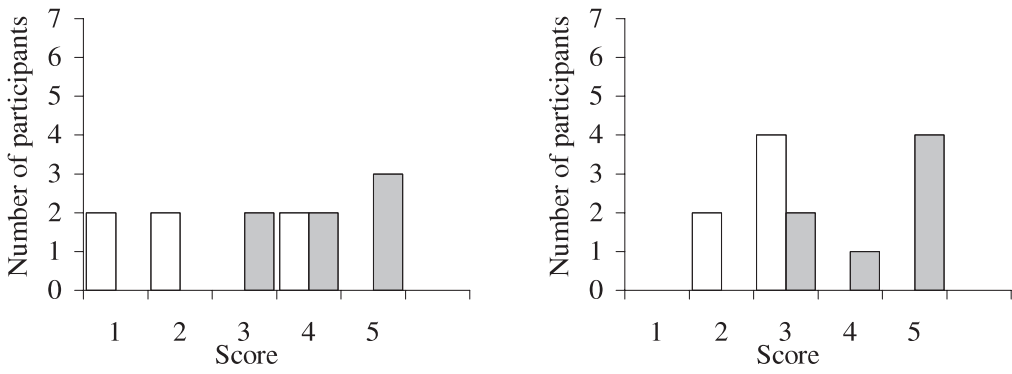

$\mathrm{U}=6.0, \mathrm{p}<0.05$

$\mathrm{U}=4.0, \mathrm{p}<0.05$

ANCHORED IN SCENARIO AS PRESENTED

No scenario

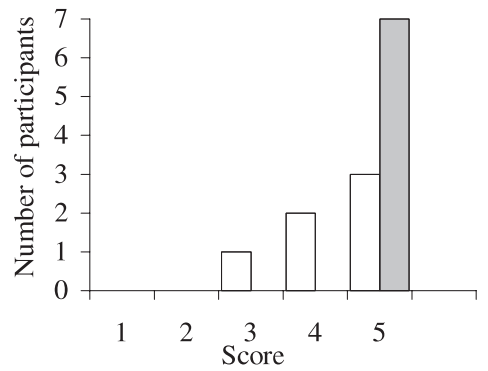

$\mathrm{U}=10.5, \mathrm{~ns}$

Figure 1. The performance of HS (shaded bars) and LS (white bars) children in play with a doll (bathing and bedtime).

children was $3.6(S D=1.4)$ and the LS children $2.0(S D=1.3)$; in the structured condition, the mean for HS children was $2.7(S D=$ 1.2) and for LS children $1.8(S D=0.4)$. Although neither of these group differences reached significance, there was a consistent trend for the HS children to score more highly.
Ascribing individual character(s) to the doll(s) in the narrative. Here exploratory two-tailed Mann-Whitney tests indicated significant differences $(p<.05)$ only on the structured conditions of each task; by way of illustration of the results in these conditions, in Task 1, HS mean score $3.9(S D=0.9)$ and LS $2.5(S D=$ 


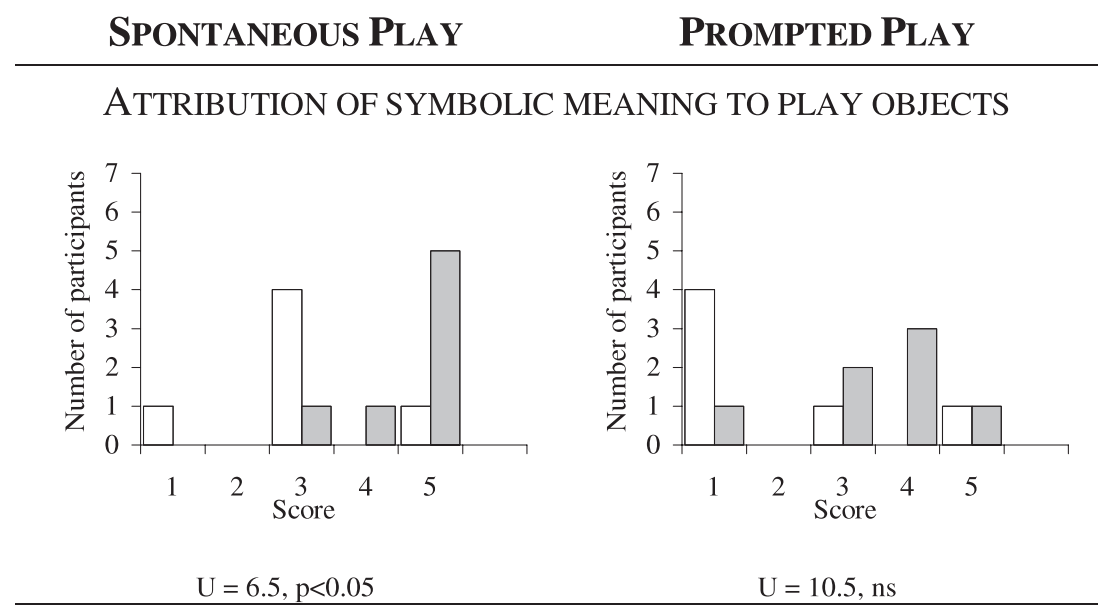

INDIVIDUAL ROLES ANCHORED IN PLAY OBJECTS
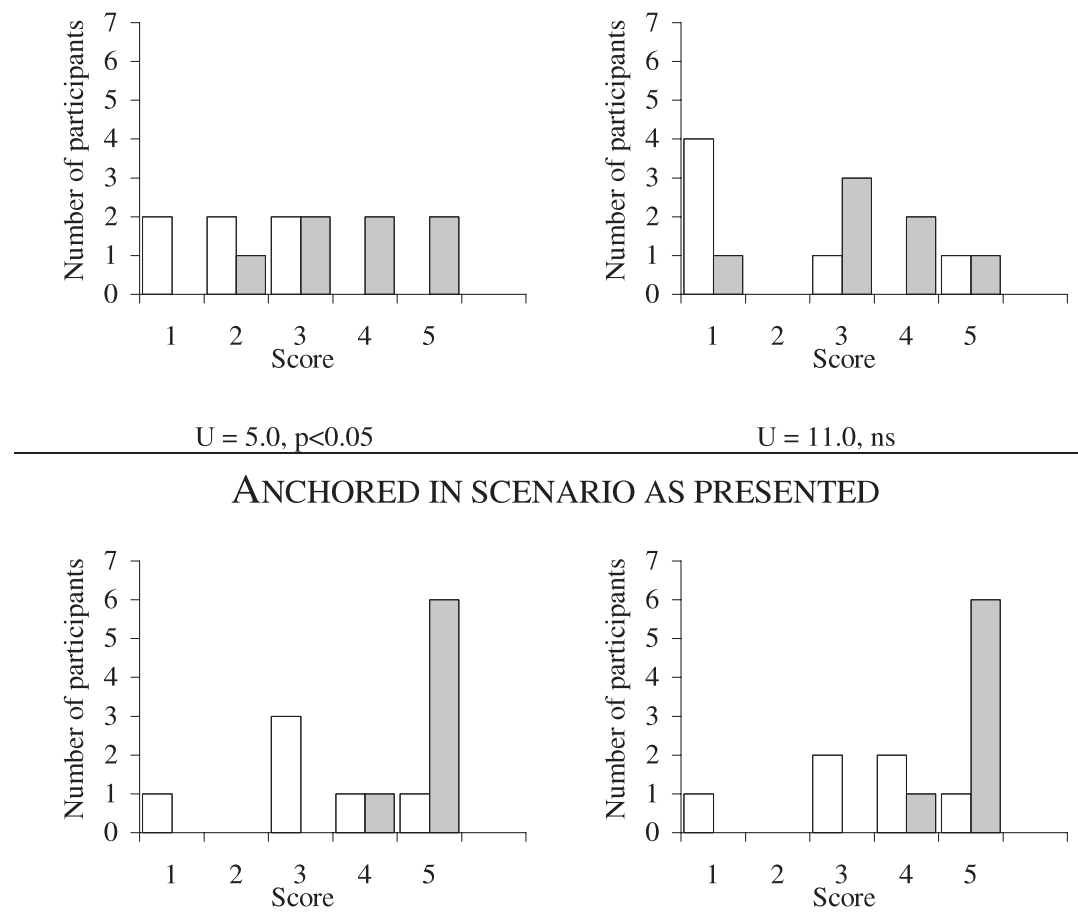

$\mathrm{U}=11.0, \mathrm{~ns}$

\section{ANCHORED IN SCENARIO AS PRESENTED}

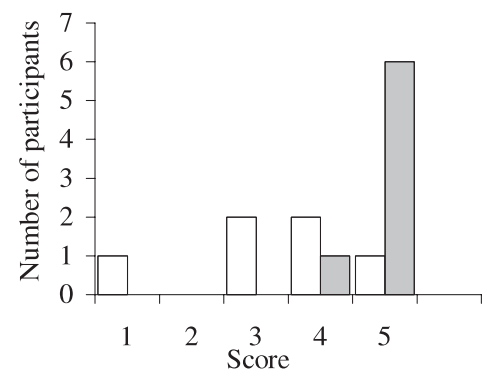

$\mathrm{U}=4.5, \mathrm{p}<0.05$

$\mathrm{U}=5.0, \mathrm{p}<0.05$

Figure 2. The performance of HS (shaded bars) and LS (white bars) children in play with two figures (playground scene).

$0.5)$; and in Task 2, HS $4.7(S D=0.5)$ and LS $3.5(S D=1.0)$.

Two illustrations of play by LS children are given in Appendix A. In these examples the children's relative failures to attribute symbolic meaning to play materials, and to attribute roles to play figures, are especially striking.

\section{Study 2: A Comparison Between the Socially Able Blind Children and Sighted Children}

The purpose of this supplementary study was to establish whether the symbolic play of the socially able blind children who took part was 
Table 2. Participants' peak performance for spontaneous play with a doll (Task 1) and with two figures (Task 2)

\begin{tabular}{|c|c|c|c|c|c|c|c|c|c|c|}
\hline & \multicolumn{5}{|c|}{$\begin{array}{c}\text { Task } 1 \\
\text { Scores }(\max =5)\end{array}$} & \multicolumn{5}{|c|}{$\begin{array}{c}\text { Task } 2 \\
\text { Scores }(\max =5)\end{array}$} \\
\hline & 1 & 2 & 3 & 4 & 5 & 1 & 2 & 3 & 4 & 5 \\
\hline \multicolumn{11}{|c|}{ Attribution of Symbolic Meaning to Play Objects } \\
\hline $\mathrm{HS}(n=7)$ & 0 & 0 & 0 & 0 & 7 & 0 & 0 & 0 & 0 & 7 \\
\hline $\operatorname{LS}(n=6)$ & 0 & 2 & 2 & 1 & 1 & 1 & 0 & 1 & 1 & \\
\hline \multicolumn{11}{|c|}{ Individual Roles Anchored in Play Objects } \\
\hline $\mathrm{HS}(n=7)$ & 0 & 0 & 0 & 2 & 5 & 0 & 0 & 0 & 2 & 5 \\
\hline LS $(n=6)$ & 1 & 2 & 0 & 0 & 3 & 2 & 2 & 0 & 1 & 1 \\
\hline \multicolumn{11}{|c|}{ Spontaneous: Anchored in Scenario as Presented } \\
\hline $\mathrm{HS}(n=7)$ & - & - & - & - & - & 0 & 0 & 0 & 0 & 7 \\
\hline $\operatorname{LS}(n=6)$ & - & - & - & - & - & 1 & 0 & 1 & 0 & 4 \\
\hline
\end{tabular}

different from that of sighted children of similar age and ability.

\section{Participants}

The congenitally blind children who were involved in this comparison were the same as those described above, with one exception. To achieve closer matching with sighted children, it was necessary to replace one child (with a diagnosis of optic atrophy, CA $=107$ months, IQ = 57) with another whose diagnosis was of retinopathy of prematurity, $\mathrm{CA}=$ 80 months, IQ $=115$. This meant that the group characteristics were as follows: HS blind group mean $\mathrm{CA}=86.6$ months $(S D=8.3$ months), range $=75-96$ months; $\mathrm{MA}=87.6$ months $(S D=12.9$ months $), \mathrm{IQ}=101.4(S D=$ 12.9); and sighted children mean $\mathrm{CA}=82.1$ months $(S D=9.8$ months $)$, range $=68-93$ months; mean $\mathrm{MA}=83.7$ months $(S D=12.7$ months $)$, mean IQ $=102.1(S D=12.4)$.

\section{Results}

The levels of attentiveness were very similar in the children of each group, in that with one minor exception (in the structured part of Task 2, when the blind children were given a mean rating of 4.3 out of 5), the mean ratings of each group for every condition were 4.5 or above for attentiveness.

In the following we cite two-tailed tests of significance for the reason that we did not make a prediction that either group would score more or less highly than the other. Given that in general, scores varied little across tasks and were often near ceiling, we combine ratings across conditions to illustrate the similarities between the HS blind and the sighted children. Given that the maximum score for each rating was 5 , the total scores were 20 for symbolic meaning and role attribution (where there were two ratings for each of the two tasks) and 15 for narrative anchorage (where this was not rated for the first part of Task 1).

The attribution of symbolic meaning. There was not a significant group difference. All but one HS blind child scored at least 17 out of 20 (the one exception being a child who scored 14) and this was the case for all the sighted children (among whom five achieved ceiling scores).

Individual roles anchored in play objects. It was only in this respect that the group difference was significant. Among the HS blind chil- 
dren, the scores out of 20 were 11, 13, 14, 16, 16, 17, and 18; among the sighted children (with one of the scores prorated for the final condition, which the child did not complete) the scores were $16,16,18,18,19,19$, and 19 (Mann-Whitney $U=7.0, p<.05$, two tailed). When the peak ratings were considered, in each condition the HS blind children achieved a mean score of at least 4 out of 5 .

Anchorage in the scenario as presented. There were maximum scores for all but one of the HS blind children (who scored 13 out of 15), and all but three of the sighted children (who achieved at least 13 out of 15). Once again, therefore, there was not a group difference.

Additional measures. There was little to distinguish the more socially able and sighted children in terms of affective relation toward the doll and ascribing individual characters to the doll(s) in the narrative.

\section{Discussion}

The results from this study reveal that congenitally blind children who were judged by teachers to have difficulties in their social relations, and who tended to have relatively high scores on the CARS but did not satisfy the diagnostic criteria for autism, had limitations in symbolic play when compared with languagematched congenitally blind children who were socially able. These group differences extended to all three of the measures on which contrasts had been predicted: the attribution of symbolic meanings to play objects, individual roles anchored in play objects, and anchorage in the play scenario as presented by the adult.

There was also evidence that the limitations were relative rather than absolute. In particular, ratings of "peak performance" on Task 1, with a single doll, revealed that the majority of children showed some instances of each quality of symbolic play. An additional comparison between the HS group of blind children and matched sighted children yielded evidence that there was little to distinguish the play of these groups. This finding confirmed observations that by middle child- hood, symbolic play can develop to sophisticated levels in congenitally blind children who are socially more able.

These results point toward a relation between limitations in symbolic play and restricted social relatedness in congenitally blind children, a relation that is independent of age and verbal ability as assessed by the WISC. They also serve to reconcile apparent contradictions in previous research. As the behavior of the socially able children attests, lack of vision is not a barrier to developing fully elaborated symbolic play. More than this, even those blind children who showed limitations in symbolic play also displayed instances of symbolic play that featured the attribution of symbolic properties to play materials and roles to play characters. On the other hand, it was also the case that socially less able congenitally blind children showed abnormalities in symbolic play, in that this was inconstant and often limited in character, not only in the application of symbolic meanings but also in the ascription of roles to play figures. The present study also provides additional suggestive evidence (only) that socially more able blind children have a more marked tendency to display an affective relation with the doll of Task 1 , and to ascribe individual characters to the doll and reciprocally engaged figures in the structured conditions of the tasks.

Before considering the theoretical implications of these results, it is worth stressing certain features of the study. First, the results apply to children between the ages of 5 and 9 years, and therefore, they do not provide direct evidence on whether congenitally blind children, whether or not socially impaired, are delayed or otherwise abnormal in the early development of symbolic play. As with other studies of children well past the age when typically developing children begin to show symbolic play, the present investigation reveals what congenitally blind children can achieve, and the respects in which some of the children still have limitations, but points only indirectly to the obstacles they may face in deriving their abilities early in life. Second, the study was restricted to children who had total or near-total blindness from birth, and the findings may be restricted to this group of 
profoundly visually impaired children. Of course, it is a strength of the study that by constituting two matched groups of children who had blindness of this kind, we were able to control for a number of factors to do with lack of visual experience (both present and past) that are conflated when blind and sighted children's symbolic play abilities are tested and compared. Third, the setting of the tasks was one in which the children's play was scaffolded and encouraged by an adult, and some of the children might well have shown more marked differences from each other and from sighted children if they were studied playing by themselves (as in the study of younger children by Hughes et al., 1998). This is theoretically important, insofar as the functional properties of the children's symbolic representational skills, for example, as generalized to a variety of settings, may be overestimated by tests that provide adult scaffolding and prompting.

There is also one factor that complicates the interpretation of the findings in this as in almost all studies of congenitally blind children: the aetiologies of the children's visual impairments. In the present case, the LS group featured four children with the diagnosis of Leber amaurosis, whereas this diagnosis was absent among the HS children. This raises the possibility that although this condition was associated both with social impairment and with limitations in symbolic play, these functional abnormalities might not have had a direct developmental relation to one another. Indeed, it has been suggested that children with Leber amaurosis might have a predisposition to autistic-like clinical features (Rogers \& Newhart-Larson, 1989). On the other hand, the cases of Leber amaurosis were not atypical of the LS group, and the children with other diagnoses showed similar limitations in symbolizing. In addition, there were two children with Leber amaurosis (and one with Norrie disease) who featured among the nonautistic and relatively able congenitally blind children studied by Brown et al. (1997), so it is not clear how far, in general, specific diagnoses are associated with social impairment and limitations in symbolizing. Nevertheless, further studies are required to clarify this issue.
When it comes to considering the broader implications of the study, two matters are of special interest. The first is whether the present results are potentially informative about the kinds of difficulty that are faced by congenitally blind children in developing the ability and propensity to symbolize. The second is whether the nature of these difficulties might clarify (and be clarified by) the deficits in symbolizing seen in children with autism, whether sighted or congenitally blind.

With regard to the first of these issues, it is clear that congenitally blind children's limitations in symbolic play may not always be associated with, and therefore not caused by, impaired general cognitive abilities, at least those linguistic abilities tested by the WISC. Despite group similarity in scores on the WISC, it was the children with limited social engagement who were those with a relative dearth in symbolic play. Moreover, the differences in symbolic play were not simply in the attribution of symbolic properties to play materials, but also in features of role taking. Although an association between disabilities does not establish whether they exist in causal relation to one another, the facts that social impairments are common among congenitally blind children from early in life, and that social engagement and role taking are often considered to underlie symbolic play in typical development (e.g., Hobson, 1990, 2002; Werner \& Kaplan, 1984; Wolf \& Gardner, 1981), suggest that the origins as well as expression of their limitations in symbolic play may arise in the social domain.

Such an account is compatible with the overlap between congenital blindness and autism. Although comorbidity of this kind might arise for a variety of reasons, for example, congenital blindness might be associated with neurological impairments common in sighted children with autism (e.g., Cass, Sonksen, \& McConachie, 1994; Rogers \& NewhartLarson, 1989), it is striking that blind children show a range of clinical features of autism. There does not seem to be a clear boundary between blind children with the syndrome of autism and those who have very few "autistic features" (Brown et al., 1997); such autistic features in nonautistic blind children are very 
similar to features in sighted children with autism, and there is an association between autistic-like social impairments and other features of autism (Hobson \& Bishop, 2003); and there are subtle differences between blind and sighted children with autism in degree of social impairment, suggesting that blindness per se may be making a pathogenic contribution in the former group (Hobson et al., 1999). The present study has supplemented this evidence with further indication of a close relation between two autistic-like clinical features in nonautistic congenitally blind children, namely social impairment and limitations in symbolic play.

According to the present perspective, it was to be expected that these same children would also be given relatively high scores on the CARS, reflecting the fact that they showed a number of clinical features characteristic of autism. Yet this might prompt the question that if the children can be said to fall in the "autism spectrum," then why does one need to suppose that blindness is relevant for the association among specific clinical features? Although the possibility exists that some other (e.g., neurologically based) dysfunction might account for the relation between social impairment and limitations in symbolic play in blind children, it remains the case that the diagnosis of "autism spectrum disorder" is purely descriptive, not explanatory, and that we still require an account of the prevalence and patterning of characteristic clinical features in this particular population of children. Although it might be claimed that "autistic-like tendencies" are responsible for impairments in symbolic play, this would beg the question of the nature of the tendencies involved, and in what sense they are causal.

If this reasoning is valid, then what might be the critical social-developmental influences that affect the emergence and expression of symbolic play in congenitally blind children, as well as in sighted children with autism? Hobson (e.g., 1993a, 1993b) has suggested that infants need to relate to and identify with other people's relatedness to the world, as a precondition for disembedding from their own perspective and for coming to grasp that a person may apply meanings or "descriptions" to objects and events to which they do not normally apply. The proposal is that both sighted children with autism who are unable to achieve psychological connectedness with others at the preconceptual level of nonverbal communication, and children who lack of vision, and therefore the ability to see how people's attitudes are directed toward a shared world, might be handicapped in relating to the outer-directed attitudes of others. As a result, they are predisposed to difficulties in adopting social-psychological roles (including those required for succeeding in "Theory of mind" tasks; Minter, Hobson, \& Bishop, 1998) and in ascribing such roles and applying flexible symbolic meanings to play materials. In relation to the present results, one might consider the LS group of congenitally blind children to have a long history of being weakly engaged with the attitudes and psychological orientations of others, and thereby less inclined to adopt multiple and often symbolically expressed perspectives on the materials of play; while in the case of the HS children, one can imagine how carers might have tapped their potential for social engagement so that joint orientation to a shared world might be achieved through perceptual routes other than vision. It is an important research challenge to establish the factors that determine the range of social engagement among congenitally blind children.

Here it is worth noting that in the case of playing with a single doll, scaffolding appeared to shift both groups toward higher symbolic play scores (Figure 1), an effect that has been observed in children with autism. If it is indeed the case that both congenitally blind children and sighted children with autism are limited in the degree to which they are naturally "pulled" (through identification) into the mental orientation of other people, including the kind of orientation that imbues objects with symbolic meaning, then perhaps it is to be expected that their abnormalities will be less marked when another person gives explicit emphasis both to the objects at the focus of play, and the meanings those objects are to represent. Scaffolding of this kind might promote children to adjust to objects that are stated to occupy new roles in play, especially if those roles occur within familiar "scripts," even if they are limited in the ability to discern and 
adopt such meanings through moving among person-anchored perspectives. On the other hand, in the more complex second scenario involving multiple figures, scaffolding appeared to be unhelpful to either group, and it seems likely that this reflected the task demands of following the investigator's complex actions in coordinating roles.

There are, of course, alternative approaches to explaining blind children's lack of social engagement and/or impoverishment in symbolic play. For instance, restricted communicative (including language) experience may limit their access to others' minds, and their lack of vision may affect their executive functioning or motivation to symbolize. It is also the case that the children's knowledge base is atypical, and their handicaps can affect the manner of their social compliance. In addition, if social-developmental factors play a critical role, we need to understand how relatively rich social engagement (as in the HS children) appears to compensate for lack of vision in providing the interpersonally coordinated experiences said to be critical for symbolic play. Finally, we need to account for the development of at least some aspects of language to a sophisticated level (relative to symbolic play and social interaction) even in those children who have impaired social-communicative development, a matter that may be clarified by noting how, as in the case of autism, there might be certain domains within language for which social input is less critical than others, and in particular, for which perspective-relative understanding (as in the case of deictic terms such as personal pronouns) may not be required.

Whatever the case in these respects, it may be necessary to reconsider the distinction between children's competence and performance in symbolic play (e.g., Lewis et al., 2000). As the results of the present study testify, even LS children have some ability to play symbolically, especially when assisted by an adult, but they are patchy in this respect. Just as the propensity to identify with the psychological orientation of others may be weak rather than absent, and just as congenital blindness is a relative rather than absolute handicap to understanding that particular objects and events can fall under different descriptions that include symbolic meanings, so one might imagine how individual children have a deficit in competence (in that the symbolic function is not well established) and in performance (in that potential abilities require external support for their expression, such as that provided by adult scaffolding). Certainly, as Lewis et al. (2000) propose, additional factors such as the children's ability to coordinate attention to different objects may play a role, something that might explain the present results when the children were given the structured play condition involving two miniature figures. Once again, however, cognitive and social influences might each bear on this kind of limitation.

The present study points to an important connection between the amount and nature of such play in middle childhood, and the degree of blind children's social impairment. Congenitally blind children with good social relations showed symbolic play that was as rich as that of sighted children (except, interestingly, with respect to ascribing individual roles anchored in play objects, a finding that may point to difficulty in adjusting perspectives according to specific physically located anchor points); but blind children of the same age and language ability with less good social relations showed a variety of limitations in the attribution of symbolic properties to the materials of play, and in ascribing roles to play figures. Longitudinal studies of congenitally blind children, especially studies that trace the timing, nature, and concomitants of symbolic play from early in life, might further illuminate the development of play in typically developing children and those with autism, as well as shed light on the developmental psychopathology of congenital blindness.

\section{References}

Andersen, E. S., Dunlea, A., \& Kekelis, L. S. (1984). Blind children's language: Resolving some differences. Journal of Child Language, 11, 645-664.
Bretherton, I. (Ed.). (1984). Symbolic play: The representation of social understanding. New York: Academic Press. 
Brown, R., Hobson, R. P., Lee, A., \& Stevenson, J. (1997). Are there "autistic-like" features in congenitally blind children? Journal of Child Psychology and Psychiatry, 38, 693-703.

Burlingham, D. (1961). Some notes on the development of the blind. Psychoanalytic Study of the Child, 16, 121-145.

Cass, H. D., Sonksen, P. M., \& McConachie, H. R. (1994). Developmental setback in severe visual impairment. Archives of Disability in Childhood, 70, 192-196.

Fein, G. G. (1981). Pretend play: An integrative review. Child Development, 52, 1095-1118.

Ferguson, R., \& Buultjens, M. (1995). The play behavior of young blind children and its relationship to developmental stages. British Journal of Visual Impairment, 13, 100-107.

Fraiberg, S. (Ed.). (1977). Insights from the blind. London: Souvenir Press.

Fraiberg, S., \& Adelson, E. (1977). Self-representation in language and play. In S. Fraiberg (Ed.), Insights from the blind (pp. 248-270). London: Souvenir Press.

Hobson, R. P. (1990). On acquiring knowledge about people and the capacity to pretend: Response to Leslie (1987). Psychological Review, 97, 114-121.

Hobson, R. P. (1993a). Through feeling and sight to self and symbol. In U. Neisser (Ed.), The perceived self: Ecological and interpersonal sources of self-knowledge (pp. 254-279). Cambridge: Cambridge University Press.

Hobson, R. P. (1993b). Autism and the development of mind. Hove: Erlbaum.

Hobson, R. P. (2000). The grounding of symbols: A socialdevelopmental account. In P. Mitchell \& K. J. Riggs (Eds.), Reasoning and the mind (pp. 11-35). Hove: Psychology Press.

Hobson, R. P. (2002). The cradle of thought. London: Macmillan.

Hobson, R. P., \& Bishop, M. (2003). The pathogenesis of autism: Insights from congenital blindness. Philosophical Transactions of the Royal Society, 358, 335-344.

Hobson, R. P., Brown, R., Minter, M. E., \& Lee, A. (1997). "Autism" revisited: The case of congenital blindness. In V. Lewis \& G. M. Collis (Eds.), Blindness and psychological development in young children (pp. 99-115). Leicester: British Psychological Society.

Hobson, R. P., Lee, A., \& Brown, R. (1999). Autism and congenital blindness. Journal of Autism and Developmental Disorders, 29, 45-56.

Hughes, M., Dote-Kwan, J., \& Dolendo, J. (1998). A close look at the cognitive play of preschoolers with visual impairments in the home. Exceptional Children, 64, 451-462.

Landis, J. R., \& Koch, G. G. (1977). The measurement of observer agreement for categorical data. Biometrics, 33, 159-174.

Leslie, A. M. (1987). Pretence and representation: The origins of "theory of mind". Psychological Review, 94, 412-416.

Lewis, V., \& Boucher, J. (1988). Spontaneous, instructed and elicited play in relatively able autistic children. British Journal of Developmental Psychology, 6, 325-339.

Lewis, V., Norgate, S., Collis, G., \& Reynolds, R. (2000). The consequences of visual impairment for children's symbolic and functional play. British Journal of Developmental Psychology, 18, 449-464.
Minter, M. E., Hobson, R. P., \& Bishop, M. (1998). Congenital visual impairment and "theory of mind." British Journal of Developmental Psychology, 16 , 183-196.

Parsons, S. (1986). Function of play in low vision children (Part 2): Emerging patterns of behavior. Journal of Visual Impairment and Blindness, 80, 777-784.

Piaget, J. (1962). Play, dreams and imitation in childhood. New York: Norton.

Preisler, G. M. (1991). Early patterns of interaction between blind infants and their sighted mothers. Child: Care, Health and Development, 17, 65-90.

Preisler, G. M. (1993). A descriptive study of blind children in nurseries with sighted children. Child: Care, Health and Development, 19, 295-315.

Preisler, C. (1995). The development of communication in blind and in deaf infants-Similarities and differences. Child: Care, Health and Development, 21, 79-110.

Preisler, G., \& Palmer, C. (1989). Thoughts from Sweden: The blind child at nursery school with sighted children. Child: Care, Health and Development, 15 , $45-52$.

Rogers, S. J., \& Newhart-Larson, S. (1989). Characteristics of infantile autism in five children with Leber's congenital amaurosis. Developmental Medicine and Child Neurology, 31, 598-608.

Rogers, S. J., \& Puchalski, C. B. (1984). Development of symbolic play in visually impaired young children. Topics in Early Childhood Special Education, 3, 57-63.

Sandler, A. M., \& Hobson, R. P. (2001). On engaging with people in early childhood: The case of congenital blindness. Clinical Child Psychology and Psychiatry, 6, 205-222.

Sandler, A. M., \& Wills, D. M. (1965). Preliminary notes on play and mastery in the blind child. Journal of Child Psychotherapy, 1, 7-19.

Schneekloth, L. H. (1989). Play environments for visually impaired children. Journal of Visual Impairment and Blindness, 83, 196-210.

Schopler, E., Reichler, R. J., \& Renner, B. R. (1988). The Childhood Autism Rating Scale (CARS). Los Angeles: Western Psychological.

Slade, A., \& Wolf, D. P. (1994). Children at play: Clinical and developmental approaches to meaning and representation. New York: Oxford University Press.

Smith, N. R., \& Franklin, M. B. (Eds.). (1979). Symbolic functioning in childhood. Hillsdale, NJ: Erlbaum.

Tait, P. E. (1972). A descriptive analysis of the play of young blind children. Education of the Visually Handicapped, 4, 12-15.

Troster, H., \& Brambring, M. (1994). The play behavior and play materials of blind and sighted infants and preschoolers. Journal of Visual Impairment and Blindness, 88, 421-432.

Vygotsky, L. (1976). Play and its role in the mental development of the child. In J. Bruner, J. Jolly, \& K. Sylva (Eds.), Play: Its role in development and evolution (pp. 537-554). Harmondsworth: Penguin.

Werner, H., \& Kaplan, B. (1984/1963). Symbol formation. Hillsdale, NJ: Erlbaum.

Wills, D. M. (1965). Some observations on blind nursery school children's understanding of their world. Psychoanalytic Study of the Child, 20, 344-364.

Wills, D. M. (1968). Problems of play and mastery in the blind child. British Journal of Medical Psychology, 41, 213-222.

Wills, D. M. (1979a). "The ordinary devoted mother" and 
her blind baby. Psychoanalytic Study of the Child, 34 , 31-49.

Wills, D. M. (1979b). Early speech development in blind children. Psychoanalytic Study of the Child, 34, 85-117.

Wills, D. M. (1981). Some notes on the application of the diagnostic profile to young blind children. Psychoanalytic Study of the Child, 36, 217-237.

Wing, L., \& Gould, J. (1979). Severe impairments of social interaction and associated abnormalities in children: Epidemiology and classification. Journal of Autism and Developmental Disorders, 9, 11-29.

Winnicott, D. W. (1971). Playing and reality. London: Tavistock.

Wolf, D., \& Gardner, H. (1981). On the structure of early symbolisation. In R. L. Schiefelbusch \& D. D. Bricker (Eds.), Early language: Acquisition and intervention (pp. 287-327). Baltimore, MD: University Park Press.

Wolf, D. P., Rygh, J., \& Altschuler, J. (1984). Agency and experience: Actions and states in play narratives. In I. Bretherton (Ed.), Symbolic play (pp. 195-217). Orlando, FL: Academic Press.

Wulff, S. B. (1985). The symbolic and object play of children with autism: A review. Journal of Autism and Developmental Disorders, 15, 139-148.

\section{Appendix A}

The following two vignettes illustrate the play of two LS (socially impaired) children, one from the higher functioning end of the range and the other with more limited cognitive ability:

\section{Vignette 1: A Girl Aged 5 Years 10 months With Leber Amaurosis and a Verbal IQ of 106}

Task 1. When initially introduced to the doll as "Ann," and asked how she wanted to play with her, this child answered: "I'll give her a shower." She held the doll by the torso, flat and facing upward in her lap. To the doll she asked: "Do you like that?" and followed it with "Put Ann in the shower. Do you like that?" This was not accompanied by any physical action toward the doll. She began to repeat a rhyming phrase, intoning every word delightedly and with gusto, "Scrub a dub dub, whishy whashy whoosh; scrub a dub dub, whishy whashy whoosh." Throughout she held the doll limply in her lap, without attention, concentrating totally on the rhyme. After a few repetitions she asked the experimenter to join in.
At this point the investigator led the child through the washing sequence involving symbolic play materials as described in the text, and asked the child to continue bathing Ann and then to get her ready for bed. The child listened to the experimenter's play routine, but then continued this by making several repetitions of the phrase quoted above. Her attention seemed to be focused on trying out different emphases on particular words, for instance specially sounding the final "whoosh." Then she asked the experimenter to join in, enunciating clearly and strongly exactly how he should sound each word. They repeated the phrase through twice to her delight, then she suddenly called out "Finished!" and picked the doll out of the bowl with: "Come on Ann, let's go to bed!" She asked to read a story to Ann on the bed, which involved repeating the "Whoosh" song over and over.

Task 2. This involved the most sophisticated level of play, with figures offered in potentially reciprocal role relationships involving conflicting emotions. When the child was asked to make up a story with the two figures (referred to as "children"), she held the two figures in her hands and said: "This is a very funny book, it's about Whooshes. Let's pretend a story. It's about these two children, Whoosh and Whooshy. Whooshy was trying to do a swhoosh. 'What are you doing here?' says Whoosh. 'Do you want a 'eh' aye?' Whooshy, Whoosh's sister, was trying to do a whoosh." During this time she continued to hold the figures in front of her, tapping them together but apparently without attention, concentrating on her story.

When subsequently the investigator playacted the story about the two figures having a dispute, and asked, "Can you make up what happens next in the story?," the child gave a start, said "Oh!," and continued: "There's a little boy called Swhooshy. He always wanted money. He really enjoyed playing in the ... "Yeah", said Swhoosh. "Would you like that ih'hy?" "Yeah" said Swhoosh. "What should he have said, Mr. B?" she interjected, calling to the investigator (MB). He replied, "I don't know what he should have said," and she went on "Because Swudge is a tu'unn. A very big 
ih'hy with a very long kih'hy. Tu'unn is French for huh'unn." Throughout, she kept the block figures in her hands, sometimes tapping them together, but without connecting them to her story.

\section{Vignette 2: A Girl Aged 8 Years 7 Months With Leber Amaurosis and a Verbal IQ of 85}

Task 1. When asked how she would like to play with the doll Ann, she replied: "Lift it up," and lifted the bowl gently with the doll inside, exploring round it slowly and with a little trepidation. She touched the doll briefly then put the bowl down in her lap, rocking it gently with both hands and smiling occasionally. The experimenter asked what she was playing, and added: "Do you want to play with Ann?" "Yes," she said and leaned her head down into the bowl in her lap, feeling the doll.

When the investigator enacted the bathing scenario and the child was asked to make up what happens next, she replied "Wash her hair," felt the doll's hair for a few seconds then stopped. After a pause she was asked "Now what happens?" and she replied: "Get out," holding the doll up above the bowl. After a few moments of silence, she put the doll back in the bowl and felt around it, then took the doll out again. She found and picked up the small cloth, made a single brush of the doll's hair and body, and put both of them down. This completed her play.
Task 2. When introduced to the new play materials and asked: "Can you make up a story with the two children?," the child sat with the two block figures held limply in one hand, silent. The investigator repeated the question. The child replied "No" and continued to sit quietly, handling the blocks but not giving them meaning. When she was asked again, "Do you want to play a game with them?" she answered "Yes," but sat in silence for a further 20 s. She was prompted with: "What happens? Can you make up a story with the two children and the classroom?" and she felt around to pick up the box. She put the two block figures inside, let them go and without speaking, then held up the box with one hand.

When the investigator enacted the play conflict between the play figures and asked "Can you make up what happens next in the story?," the child replied "It's drinks time." She held one block figure in each hand and tapped them in turn rhythmically on the floor, then onto each other. She did this in silence for about $1 \mathrm{~min}$. Then she was prompted whether she'd like to make up a story with "Karen and Jane." She said, "The teacher says, 'In-time", (i.e., return to class at the end of play time), with a raised voice and higher tone for the teacher, and then became quiet again. She was prompted in a similar way once more, and replied "Time for lunch," again with slightly raised voice and tone. During this she continued to tap the blocks together in front of her. Here the play ended. 